\title{
Enhancing Organizational Project Management Maturity: a framework based on the value focused thinking model
}

\author{
Joana Coelho Viana ${ }^{a *}$, Caroline Maria de Miranda Mota ${ }^{\mathrm{a}}$ \\ aniversidade Federal de Pernambuco, Recife, PE, Brasil \\ *joanacviana@hotmail.com
}

\begin{abstract}
Although organizational project management maturity models have been well explored, they have been criticized as being ineffective as firms continue to face difficulties in improving their project management practices. Based on a literature review, an alternative methodology was developed, and the arguments for the proposal were analyzed. The analysis demonstrated the importance of integrating a decision making model to develop initiatives toward project management institutionalization appropriate to the organizational context and strategies. This paper proposes a method for the maturity process supported by a problem structuring model: Value-Focused Thinking. This method integrates a reflective analysis into the maturity evaluation process to provide more efficient action plans. The proposed approach provides a new perspective for assessing and planning organizational project management maturity in terms of concentrating on the alignment with organizational strategies. A case study is presented to illustrate its applicability.
\end{abstract}

Keywords

Decision making. Organizational project management. Maturity models. Problem structuring models.

\section{Introduction}

Maturity in project management has been pursued by companies of all industries. It seems that firms are facing more difficulties in implementing than in drawing up organizational strategies (Meskendahl, 2010) and, thus, projects have been seen as an instrument for implementing the intended strategies (Cleland \& King, 1999; Dietrich \& Lehtonen, 2005; Grundy, 2000; Pennypacker, 2005).

'Maturity' is defined as "[...] the state of being mature; fullness or perfection of development or growth [...]" (Simpson \& Weiner, 1989). Any organization aims to achieve the perfect development of their abilities in managing projects. According to Shi (2011), maturity will affect the value which an organization can gain by implementing project management. As a consequence, maturity in project management turns out to be pursued by different organizations as are Project Management Maturity Models (PMMMs) that emerged as tools through which an organization could move toward perfect development in project management by conducting a progressive maturity process within the organization.

Although maturity models have been well explored over the past 20 years, they have been severely criticized (Ahlemann et al., 2009; Mullaly, 2014). An essential issue tackled in this article is whether PMMMs in their current form are able to consider the organizational context so that they can provide proper guidelines for developing project management within an organization. Given the numerous best practices and capabilities involved, improving maturity requires a properly structured action plan (Crawford, 2006) that, in turn, requires a holistic analysis (International Project Management Association, 2013; Williams et al, 2014) of all types of organizational concerns in order to maximize the investments in project management competences. 
As organizations are continuously looking to improve project management, they have increasingly adopted PMMMs even though these have received numerous criticisms (Albrecht \& Spang, 2014). Recognition of this issue is also evidenced by the large investments made by businesses, governments and the third sector in developing skills and abilities in this area (Söderlund \& Maylor, 2012). Indeed, research studies have shown significant relationships between maturity and tangible and intangible values (Berssaneti et. al., 2012; Moraes \& Kruglianskas, 2012; Thomas \& Mullaly, 2008), which reinforces the worth of applying this tool. On the other hand, the stream of criticism triggers the need for a further understanding of PMMM frameworks and how this tool could be better used.

In resumé, project management methodologies and practices are recognized as an instrument for achieving organizational objectives. PMMMs have been applied in order to develop organizational capabilities in managing projects. They aim to prescribe how an organization can reach its desired level of project management maturity. This should guide how investments are made in project management training, practices, systems, time, tools, techniques, etc. Nevertheless, currently, a stream of researchers has criticized the abilities of these models to provide proper directions, since the organizational context is usually ignored (Brookes \& Clark, 2009; Killen \& Hunt, 2013; Kujala \& Artto, 2000; Mullaly, 2014). The evaluation of maturity through PMMMs has the essential function of identifying the potential room for improvement. On the other hand, the organizational context directly influences the return obtained from each investment in project management.

This paper aims to support companies in implementing changes and making improvements in a structured way, by proposing an integrated framework which comprises a project management maturity model, a group-decision model and a structuring problem method. In their current form, PMMMs are not able to capture properly the organizational context in order to decide how and which areas to improve. Given that a path for project management improvement has been seen as the most valuable benefit of applying a PMMM (Crawford, 2006; Pennypacker, 2005), we argue that the benefits of applying a PMMM can be significantly enhanced by the proposed multi-criteria decision aid model. This paper seeks to describe the main assumption underlying PMMM frameworks and, then, discuss how managers could make better and holistic decisions using the currently available PMMMs in order to maximize their investments. A proposition is presented and further tested in order to evaluate its usefulness in a real case.
This paper is organized as follows. The next section places the domain of PMMMs in context and discusses the issues on which the proposed approach is grounded. Section 3 describes the research methodology and gives a brief description of assumptions for the proposed approach. Then, an overview of the proposed approach is presented, following which some practical issues are discussed by applying the model in a Brazilian public organization. Finally, there is discussion of some issues while the concluding remarks show the theoretical connections and the contribution of the present study to the project management research.

\section{Project Management Maturity Models}

PMMMs have been applied as a means by which to conduct the maturity process in a systematic and structured way (Programme and Project Management Maturity Model, 2010). The basic concept of maturity drives organizational processes to continuous improvement and so requires a thorough understanding of an organization's current position and where it aims to be in the future. Initially, PMMMs were limited to the diagnosis of the level of maturity of project management within an organization. However, it was soon seen that it becomes strategic to determine the stage of maturity in order to establish a plan of action that will enable organizations to achieve their desired goals (Cleland \& King, 1999). According to Shi (2011), maturity will affect the value which an organization can gain by implementing project management.

Numerous project management models have been created, especially after the 1990s, with a view to developing organizational maturity, since higher levels of maturity suggest the ability to get better results from projects. They set out to evaluate the state of a company's expertise and support with regard to directing efforts for future development. Models that have been used to assess project management maturity include, but are not limited to: Capability Maturity Model Integration - CMMI (CMMI Product Team, 2001), the Organizational Project Management Maturity Model - OPM3 (Project Management Institute, 2008), the Project Management Maturity Model (PMMM) developed by Kerzner (2001), the Project Management Process Maturity (PM)2 Model introduced by lbbs \& Kwak (2000), which uses a methodology that calculates return on investment in project management, the Portfolio, Programme, and Project Management Maturity Model - P3M3 developed by the Office of Government Commerce OGC of England (Programme and Project Management Maturity Model, 2010) and PM Solutions' Project Management Maturity Model (PMMM) from the United 
States Center for Business Practices (Crawford, 2002). Examples of national models are those developed by Rabechini Junior \& Pessôa (2005) and Cristofari Junior et al. (2010).

Despite the diversity of models and except for some differences, they converge on a conceptual framework, comprising well-established processes through which an organization develops itself in a systemic and planned way to achieve a desired future state. It is usually divided into five linear steps that, in general, range from an initial step to repeatable, refined, managed and optimized ones (Jugdev \& Thomas, 2002). The last stage is the best or perfect one. It shows the potential improvements resulting from a higher maturity level. However it is up to the organization to decide if it is desirable to improve to the next stage (Wendler, 2012).

The standardized approach usually evaluates whether processes are defined, established, applied, controlled and continuously improved; to what extent an organization has implemented project management; and which specific capabilities have been developed. The assessment informs the degree of maturity in project management, which can be used for carrying out benchmarking and facilitating the improvement of performance (Jia et al., 2011).

In general, PMMMs and research consider adopting "best practices" as a way of achieving organizational project management maturity (Killen \& Hunt 2013). Then, after a maturity evaluation, some PMMMs will produce a list of recommended best practices to be implemented and capabilities to be developed. These recommendations usually reflect the best practices that are in use in successful organizations (Killen \& Hunt, 2009). Depending on the degree of maturity, the list of recommendations could be extremely long and organizations may have to prioritize which initiatives to invest in. Some PMMMs, especially those developed by well-known bodies of knowledge, provide directions for improving project management using special tools. However, how the evaluation of maturity and organizational strategies are balanced towards decision-making is not explicit and an organization might pay for assessment by special software or contract a specialized team to do so.

Despite all their similarities, PMMMs differ from each other with respect to their assessment methodology, such as: the number of aspects and dimensions covered and the evaluation process, how they aggregate results and levels of maturity. This happens because they are normally derived from different studies on best practices in project management (Killen \& Hunt 2009) and in this realm there is still an ongoing discussion on what is or should be the theoretical construct of project management maturity
(Pasian et al., 2012). Thus, choosing a PMMM is a managerial decision and the organizational context has to be considered to ensure the suitability of the chosen model (Wendler, 2012).

\subsection{Main criticisms and insights}

Over the years, PMMMs have been severely criticized. A stream of research claims that they lack foundations (Cooke-Davies, 2007; Jugdev \& Thomas, 2002; Mullaly, 2006), there is a lack of agreement among researchers on what comprises the project management maturity construct (lbbs \& Kwak, 2000; Pasian et al., 2012) and a lack of evidence of the relationship of maturity and perceived outcomes (Ahlemann et al., 2009; Besner \& Hobbs, 2008a; Killen \& Hunt 2013; Mullaly, 2014).

Another stream of research has criticized the structure of PMMMs by arguing that they are rigid and inflexible (Jugdev \& Thomas, 2002), processoriented (Bushuyev \& Wagner, 2014), bureaucratic and overwhelming (Albrecht \& Spang, 2014; Jugdev $\&$ Thomas, 2002) and ignore the organizational context (Killen \& Hunt, 2013; Kujala \& Artto, 2000; Mullaly, 2014).

Other studies, besides making negative criticism, have given some interesting insights into PMMMs and the evaluation of maturity. For example, Andersen \& Jessen (2003) point out that some of the most important studies on project maturity seem to have a narrow interpretation of what maturity means, as they focus primarily on what organizations and project people are doing operationally. In addition, these authors argue that measuring maturity seems to be more subjective than objective. For them, competence is related to a combination of knowledge, skills, and attitudes that influences performances.

After a critical analysis of project management maturity models, Brookes \& Clark (2009) concluded that models are used more reactively than proactively and identified there were numerous omissions. Their research findings identified the need to develop a rigorous protocol in project management maturity models as well as to identify maturity models that best stimulate a change in organizational project management.

Shi (2011), based on a literature review, highlighted the need to establishing a correct approach to implementing project management and aligning this to the organizational environment. As a result, the author proposed a path for implementing project management based on the coordination of a soft system and a hard system, that is linking organizational project management (a hard system) with the general 
management system (a soft system). However, he did not account for the external context that varies from one organization to another.

Guedes et al. (2014) emphasize the need to consolidate standards for methodology and tools in order to assess maturity so that comparisons can be made between the results of the various surveys conducted. The results of their survey identified a non-normal distribution of maturity perceptions, which may indicate that the use of the descriptor 'average', which is usually what researchers do, would not be the most appropriate one to portray an organizational maturity level. It seems that we need some detailed analysis of maturity.

Moreover, the analysis of Mullaly (2014) questions the ability of the current form of PMMMs to provide proper guidelines for improvements. This is a very important question since giving a path for project management improvement has been seen as the most valuable benefit of applying a PMMM (Crawford, 2006; Pennypacker, 2005). Thus, we will direct special attention to this point, as the focus of this study is to support managers in maximizing returns on their investments in project management.

Some earlier studies directed attention to the identification of new dimensions of maturity assessment and the differences in maturity level among different organizations (e.g. Andersen \& Jessen, 2003; Cooke-Davies \& Arzymanow, 2003; Crawford, 2006; Kerzner, 2001). Kwak \& lbbs (2000, 2002). Whereas, few, if any, really discuss and set out an explicit procedure for organizations to decide after a maturity assessment on which practices to implement or which capabilities to develop, since this may produce a vast list of recommendations. In addition, there has been no discussion on how to prioritize initiatives while taking the organizational context into account. This is because project management practices vary from one context to another (Besner \& Hobbs, 2013). If an organization wants a customized roadmap, it must contract an independent evaluator or a consultant.

As to these points, the literature review revealed the need, in maturity evaluation, to include components of subjective opinion, knowledge and attitudes (Andersen \& Jessen, 2003), developing more proactive models (Brookes \& Clark, 2009), aligning the maturity process with the organizational internal and external context (Shi, 2011) and conducting more detailed analysis of maturity Guedes et al. (2014). These could be done by analyzing separately each aspect of maturity.

It is important to incorporate characteristics and experiences of the organization into the maturity process in order to achieve more efficient action plans and enhance their implementation. Companies can adopt a diversity of maturity approaches. However, the decision process becomes more complex and increases the need to adopt formal practices of decision-making (Dietrich \& Lehtonen, 2005). Since our focus is on supporting managers to maximize investment efforts in project management, the next section will discuss how the decision-making process for selecting initiatives for improvement could be conducted in order to respond to the needs identified and, thus, to provide appropriate guidelines for improvements.

\section{Research methodology}

This research can be classified as both a conceptual and a case study. A conceptual study because it discusses the current application of PMMMs, identifying different concerns that are essential for maximizing investment in developing project management. It is classified as a case study since it has the function of explaining why a certain procedure was adopted, how it and others were implemented and what results were achieved (Yin, 2001). Some characteristics of this study could also lead to its being classified as a literature review (Miguel, 2007), since it aims to identify, explore and follow the development research in a particular area of knowledge as well as seek to play the role of transferring information and identify some prospects for future research.

In order to achieve the proposed goal, the action plan followed for this research study was over a sequence of 5 steps. First of all, past and current studies related to project management and, in particular, to project management maturity were examined in order to obtain a general and comprehensive understanding of the topic. Next, a critical analysis of the literature in maturity models was conducted in order to gather insights for building an alternative approach. Then, a new approach was developed, based on the Value-focused Thinking methodology presented in Section 5, and a real application demonstrated the usefulness of the proposed framework. Finally, a discussion and the concluding remarks show the theoretical connections and the research contribution of the present study to the project management field.

A literature review approach was conducted in order to accomplish the first two steps. For the following steps a case study approach (Tellis, 1997) was considered an appropriate methodological choice, given the holistic and exploratory nature of this investigation. In order to ensure the rigor of the research, the case study was conducted following the steps suggested by Miguel (2007), namely: defining the theoretical-conceptual structure, case planning, data collection, data analysis, and writing a report. Before the data collection, all information about the study 
and instructions for answering the questionnaire were given to the participants. Then, data was collected in two different moments. First, project management maturity was evaluated using an assessment form, which had been validated in a previous study (Kerzner, 2001). Second, the potential initiatives were generated by applying the methodology previously tested by Keeney (1996). Then, the real application was fruitful since it generated insights into the usefulness of the approach from the perspective of the participants and enabled a comparison to be made between it and an application that only assesses maturity.

\subsection{General structure for the proposed approach}

By linking the insights raised by the literature review, this paper aims to provide a methodology for supporting companies in implementing changes and making improvements in a structured way, by proposing an integrated framework which comprises a project management maturity model (PMMM), a group-decision model and is supported by a structuring problem approach.

Despite the criticism of PMMMs, Jugdev \& Thomas (2002) point out that PMMMs have significantly contributed to the field of project management as they heighten awareness of competences and provide an initial paradigm with which to assess organizational project management maturity and that this represents an essential input to support organizational development. Nevertheless, in general, organizations are not able to implement all initiatives at once nor would this be the most appropriate action. Thus, two aspects should be pointed out for the structure of the proposed framework:

i. First, since today most PMMMs are multidimensional (Wendler, 2012) and offer a vast list of best practices (Besner \& Hobbs, 2013; Killen \& Hunt, 2013), it is a challenge to define initiatives and this therefore involves a decision-making process after a maturity evaluation has been conducted. This kind of decision-making might take into account, besides the result of the maturity evaluation, the specific characteristics of the organization (e.g. strategies, experiences, limitations among other contextual factors) whereas the assumption underlying the PMMMs is that organizational project management will improve the process of managing whereby this ensures that the PMMMs will deliver the results desired by a given organization (Project Management Institute, 2012).

ii. Second, in order to gather as much information as possible and eliminate the bias involved in individual maturity self-assessments (lbbs \& Kwak, 2000; Programme and Project Management Maturity Model, 2010), an appropriate aggregation process might take place. Given the characteristics of the application of a maturity model, normally carried out by using an assessment form, with multiple choice questions and a Likert scale, what seems to be appropriate is a group decision-making method, namely voting procedure. This is one of the most common approaches used for aggregating individual preferences as argued by Saari (1999). Moreover, among the available methods, the points system from Nurmi (1983) is suitable since it is simple and easily accepted by group members (Bose et al., 1997). This procedure sums the number of times that each possible answer has been chosen. Thus, the final answer is considered to be the one which has been marked most often by the evaluators. In our situations, if there is a tie between two or more responses, the option with the lowest level of maturity will be chosen, thus following a more conservative line.

Thus, concerning these two aspects an integrated framework is proposed to support companies in implementing changes and making improvements in a structured way, as briefly illustrated in Figure 1.

In order to build the proposed framework, and given the nature of the decision, in which different characteristics of the organizational context might be taken into account, a problem structuring approach will be conducted. Problem structuring is a conceptual methodology, defined as an interactive learning process that seeks to build a formal representation, which integrates the objective components of the problem and the subjective aspects of the actors, so that the value system is explained (Eden et al., 1983).

Keeney (1996) developed a problem structuring approach, which represents a way to channel a critical resource, such as hard thinking, in order to make better decisions. The author argues that better decisions can be reached both because of insights provided by the thinking and because of specific procedures that view decisions through 'value-focused' glasses. For him, values are fundamental to all that we do and, thus, should be the driving force for the decision-making process. Therefore, the process is guided by values, rather than by alternatives. After applying the methodology, Alencar et al. (2011) concluded that applying VFT enables the parties involved to make more consistent decisions, which is any organization's goal.

The integrated framework, as briefly illustrated in Figure 1, seeks to be proactive, detailed and aligned with organizational strategies and encompasses the view of different participants, including their perspectives, 

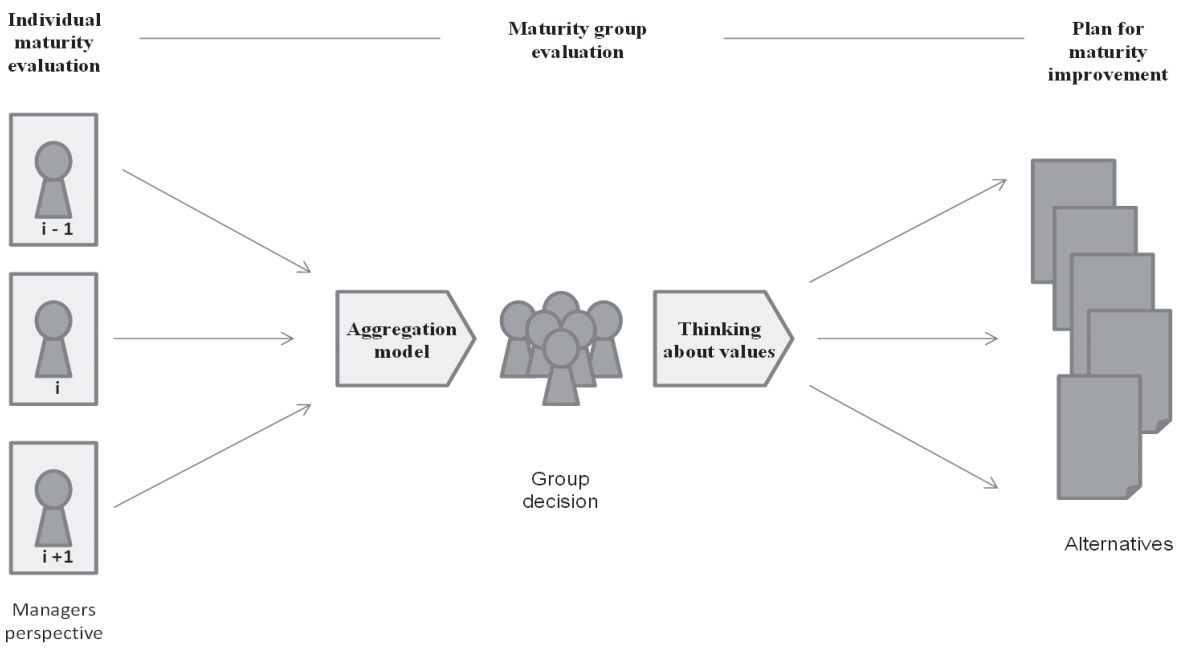

Figure 1. Aggregation of perceptions. Source: Authors, 2014.

knowledge and experiences. Therefore, this paper suggests that the integration of different models might be able to overcome some of the criticisms of PMMMs and, thus, provide appropriate guidelines for improvements. Therefore, better decisions might be made about investments.

\section{Decision-making process for maturity development}

The previous section discussed the arguments in favor of the proposed framework. This section summarizes its steps and then offers some insights about the usefulness of the approach, based on a real application in a Brazilian public organization.

\subsection{Description of the framework}

The decision-making process integrates different and distinct models for supporting decision-making, as will be demonstrated below. It aims to provide a holistic analysis, by gathering as much information as possible from the organizational context. It seeks both to make managers maximize their investment efforts in improving project management and to give them the support needed for justifying the investment and gaining commitment from the people involved. The proposed framework makes the decision process more transparent. In doing so the changes are better accepted and credibility is guaranteed (Morais \& Almeida, 2007).

The framework still utilizes a maturity evaluation form from a PMMM because this is an essential input to support the decision-making process as it significantly contributes to heightening awareness of competences (Jugdev \& Thomas, 2002) and provides directions for improvement (Kerzner, 2006). A protocol for the decision-making process is important, since in general the output of a PMMM is a list of recommendations that organizations are neither able to implement nor do they find it feasible to implement all initiatives at once, and thus some kind of prioritization process is required.

The decision-making process is also an opportunity to incorporate organizational concerns into the decision process of investments, since in general the PMMMs evaluate the operationality of process and practices (Andersen \& Jessen, 2003; Bushuyev \& Wagner, 2014) and ignore the organizational context (Killen \& Hunt, 2013; Kujala \& Artto, 2000; Mullaly, 2014).

The decision-making process proposed in this framework integrates a group-decision model and a structuring problem method, which has a specific purpose. The group decision model avoids evaluation bias by gathering different perspectives within the organization and thereafter forming a single collective evaluation (Leyva-López \& Fernandéz-González 2003). It also ensures a more transparent and reliable process which facilitates the acceptance of changes and team commitment (Morais \& Almeida, 2007). Whereas, the structuring problem method aims to stimulate a further analysis of the diagnosis of the PMMM and to create initiatives considering the organizational context, as suggested by researchers who argue that this decision might be taken in a proactive way (Brookes \& Clark, 2009), be supported by detailed analysis (Guedes et. al., 2014) and encompass the organizational context (Killen \& Hunt, 2013; Kujala \& Artto, 2000; Mullaly, 2014; Shi, 2011). This process 
is crucial to ensuring the alignment of the initiatives with the organizational strategies and the desired level and/or area for project management maturity. Investments in project management are expensive and each organization should evaluate the cost-benefit of applying each process or practice. This decision will depend on organizational characteristics, market, resource availability, among a variety of factors, which will be discussed by applying the structuring problem model in order to lead to proper decisions regarding investments on project management.

Finally, the planning phase aims to lead to the correct implementation of each initiative, while the monitoring step seeks to ensure the cyclical process of assessment. It is a learning process, and the insights gained during this process can be used to facilitate organizational improvement in a systematic and repeatable way.

\subsubsection{Maturity evaluation}

The methodology starts by evaluating the maturity of organizational project management, since without some directions, acquiring the desired maturity could take decades (Kerzner, 2006). There are several approaches with which an organization can conducted a maturity evaluation, as mentioned in the section related to PMMMs. In general, PMMMs provide self-assessment forms through which an organization can assess the level of maturity of different aspects by answering multiple choice questions that ask either for a percentage of adherence or a score on a likert scale. It is worth noting that managers might consider the organizational context in order to properly choose the model to be applied (Wendler, 2012).

After choosing the assessment form, some employees from different departments might be carefully selected to properly conduct the assessment. This should take into account their roles and responsibilities within the organization and its projects as well as their knowledge and skills of the process. If necessary, training must be provided to prepare the participants for the assessment.

Finally, the different perceptions of the participants, which sometimes conflict with each other's, are aggregated in the proposed methodology by applying the voting procedure called a points system in order to end up with a final and collective maturity evaluation.

\subsubsection{Creating alternatives for improving maturity}

The second phase of the approach consists of analyzing the results of the maturity evaluation with a view to creating initiatives for a more appropriate action plan. This process is supported by a problem structuring model and proposes a further discussion of the maturity issues in which managers must consider, besides the maturity evaluation, the organization's objectives, strategies, context, lessons learned, and so forth.

The application of the organizational project management maturity model reveals a set of issues that needs to receive special attention from senior managers and, thus, must be more intensely explored. The application of the problem structuring model (PSM) supports managers to think thoroughly about the issues and design possible alternatives, in an interactive manner. In order to maximize the investment efforts, the decision process should address all types of organizational concerns. At the same time, group interactions might well provide more efficient and creative initiatives as well as ensuring greater commitment from those involved in the process.

The proposed methodology is supported by Keeney's Value Focused Thinking (VFT) methodology (Keeney, 1996) due to its focus on values. The application of the PSM starts by examining the list of issues raised after the maturity assessment process. With the aid of Keeney's strategies for exploring objectives, the issues are translated into a hierarchy of fundamental objectives and a means-ends objective network. This end serves as the basis on which to generate alternatives, which can also be stimulated by making questions such as those suggested by the author (Keeney, 1996). The final result of this phase is a set of initiatives generated from the perspective of the organization's objectives which considers its context, peculiarities and limitations, see Figure 2.

\subsubsection{Planning and monitoring the implementation of initiatives}

After generating the initiatives that will comprise the plan toward maturity in project management, it is necessary to describe in more detail and plan the implementation of each of these initiatives. Breaking the initiatives down into smaller tasks, identifying the resources needed, the sequence of their implementation, identifying the parties involved and defining responsibilities are all planning activities.

At this stage, it is also essential to establish goals, objectives and deadlines for each action in order to ensure they are monitored over the period of implementation. For this purpose, it is suggested that key performance indicators - KPls that should be SMART: Specific, Measurable, Acceptable, Realistic and Time-bound (International Project Management Association, 2013). 


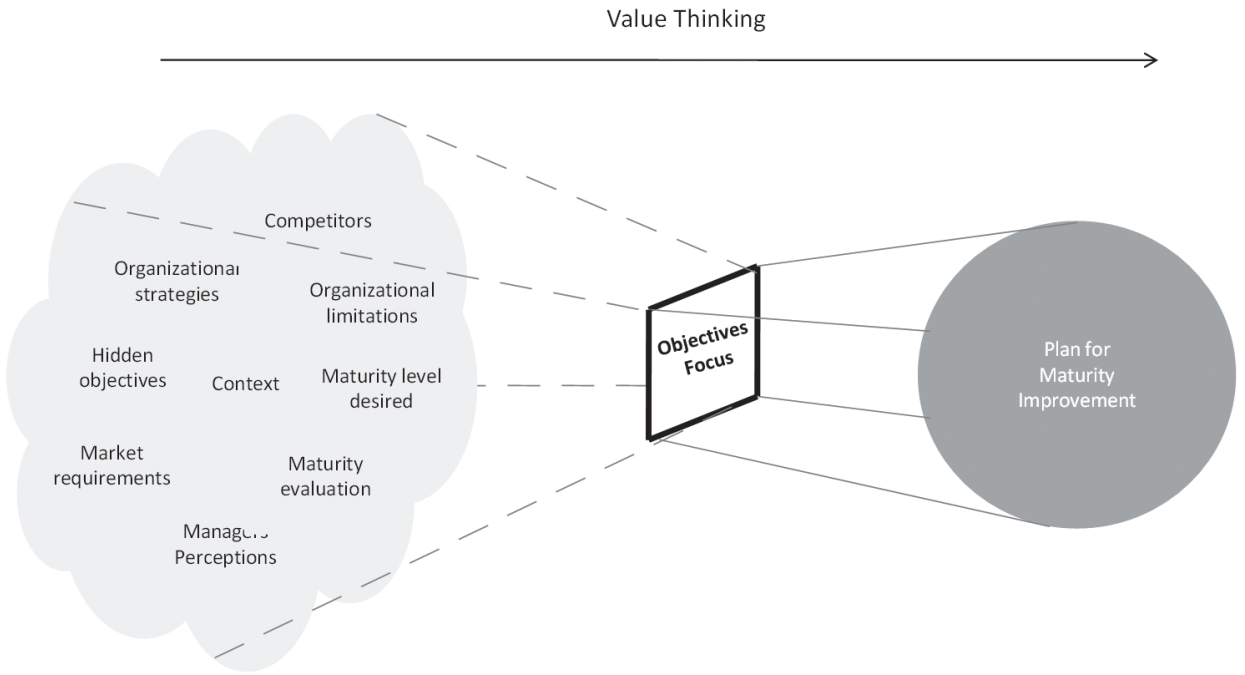

Figure 2. Exploration of Objectives. Source: Adapted from Keeney (1996).

Thereafter, the activities must be initiated, strictly in accordance with the plan drawn up in the previous step. As to the goals and targets, it is important to periodically evaluate the results obtained from the gradual implementation of the actions, which will enable deviations to be identified that may require some intervention from those responsible. Thereby, it is possible to assess the appropriateness of actions and to ensure they remain aligned to the organizational strategies.

Besides following up actions, it is also essential to monitor the plan as a whole. To assess the adequacy of the set of initiatives and the results being obtained from implementing them, the assessment instrument (Phase 1) might be reapplied. This can be repeated on a regular basis, to assess and compare the organizational maturity in project management against the established targets and competitors. The reassessments will permit organizations to identify successful initiatives and those that have failed to achieve their goals and, then, interventions will possibly be made.

Kerzner (2004) suggests conducting an assessment of maturity every three months to measure the progress of organizational project management. However, in order to obtain an effective assessment of the results of the plan, we suggest that the questionnaire should only be reapplied after the completion date set for the action plan or at least after some pre-established milestones.

After a reassessment, the organization can repeat all the steps of the systematic until all issues have been resolved and therefore the organization's desired level of maturity has been reached.
Note that the reassessment might be seen as a process for continuous learning and improvement in the organization. Unsuccessful initiatives or actions can and should be reformulated, by taking into account the errors and obstacles identified at that time. Finally, the whole process within the framework and its steps are given in Figure 3.

\section{Real application: thinking in values for improving maturity}

The framework was applied to a real case in order to evaluate its usefulness, and is described below.

\subsection{Organizational background}

The case was conducted in a public company in the electricity distribution sector in Brazil, whose main source of income depends on its projects being carried out. The company has been in business for almost 70 years. However, it has been suffering from constant delays in implementing its projects which not only jeopardizes the receipt of revenue but also generates fines imposed by regulatory agencies. Moreover, the delays in completing projects adversely affect the provision of essential services to Brazilian society.

Given the relevance of the company's projects to society and their impact on the business, the CEO proposed to work hard at institutionalizing project management in the organization. Ever since then, actions have been taken and some changes made. Recently, the essentially functionalized structure was transformed into a matrix structure, and since then the company has been trying to adopt best practices 


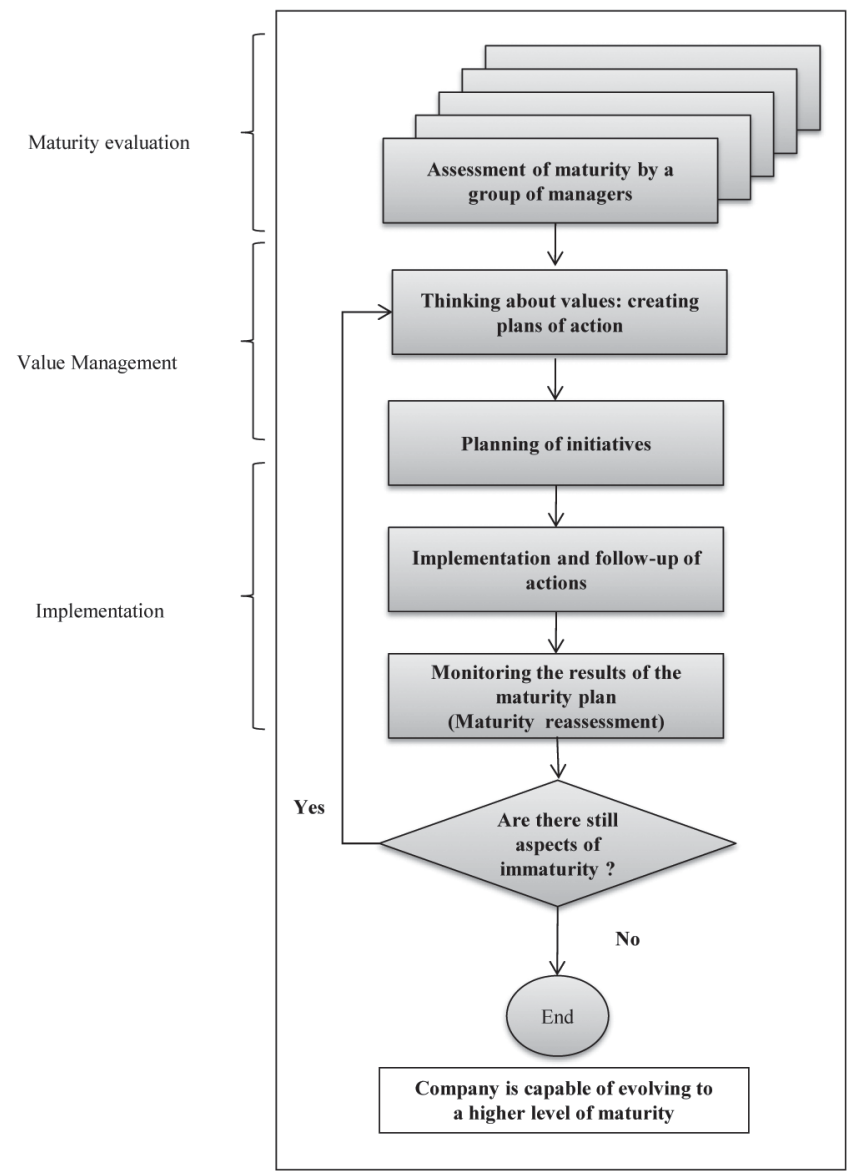

Figure 3. Framework. Source: Authors, 2014.

and tools in order to improve the conduct of their projects. In early 2012, a committee was set up which is responsible for monitoring the progress of projects and establishing standards, responsibilities, processes and practices of project management.

Currently, about 90 projects are underway in the company. These are projects that involve licensing, procurement and contracting, land management, construction, commissioning, integration and assisted operation. On average they last for 12 months and involve intense interaction between the company and its suppliers and subcontractors. The projects must meet multiple goals, including the company's strategic objectives, the deadlines set by the National Electric Energy Agency (Agencia Nacional de Energia Elétrica - ANEEL) and the budget previously approved.

The organizational culture, the matrix structure, the legal restrictions and the lack of available resources are some of the barriers to the development of project management practices in this organization. The fines imposed by ANEEL for delays in projects raise concerns about setting timelines. In this context, maturity in project management becomes critical for circumventing the constraints of the public sector and for increasing the company's efficiency and competitiveness. In order to enhance the company's initiatives, especially because of the urgency of results, the CEO decided to establish a maturity process.

\subsection{Maturity assessment by a group of managers}

First of all, the CEO previously and carefully selected the participants for the process. When creating a monitoring committee for project management in early 2012, the CEO decided to apply an assessment form to all committee members on their knowledge and involvement in ongoing projects. Each participant had to answer the form individually.

For the maturity assessment, the organization decided to adopt the well-known Project Management Maturity Model (PMMM) developed by Harold Kerzner (2001) because it consists basically of an application of an assessment forms, is simple to use 
and can be done at low cost. This maturity model was developed based on the results of a vast research study performed within different industrial sectors and in strict alignment with the principles of the Project Management Body of Knowledge - PMBok. The PMMM comprises five levels of maturity, each with its own characteristics and recommendations.

Considering the incipient level of project management activities within the organization, the PMMM level 2 assessment instrument was applied by means of a questionnaire comprising 20 questions, which encompass the five phases of the life cycle of a project, and can even identify certain elements of simultaneity between phases. The 20 questions are answered using a rating scale ranging from -3 (Strongly Disagree) to +3 (Strongly Agree). The score of each stage is determined by a specific form for each of the life cycle phases, in which there are 4 different questions related to each life cycle of the project management phase. By adding up the values of the answers, the corresponding score of each phase can be assessed, and this may vary between -12 and +12. According to Kerzner (2001), a score greater than or equal to +6 indicates that a corporation has successfully completed a particular phase of the cycle.

Since the different participants answered the form individually, in order to aggregate the different responses, the points system, described earlier, was applied. Then, the aggregated answers were cast into the appropriate form to obtain the total value for each stage of the project management life cycle and, thus, indicate whether the company has already completed some of the phases successfully. Table 1

Table 1. Evaluation of the life cycle of project management.

\begin{tabular}{|c|c|c|}
\hline \multicolumn{2}{|r|}{ Questions } & Score \\
\hline \multicolumn{3}{|c|}{ Phase: Embryonic } \\
\hline 1 & $\begin{array}{l}\text { My company recognizes the need for project management. This need is recognized at all levels of management, including } \\
\text { senior management. }\end{array}$ & 3 \\
\hline 3 & $\begin{array}{l}\text { My company has recognized the benefits that are possible from implementing project management. These benefits have been } \\
\text { recognized at all levels of management, including senior management. }\end{array}$ & 2 \\
\hline 14 & Our executives have recognized or identified the applications of project management to various parts of our business. & 1 \\
\hline \multirow[t]{2}{*}{17} & $\begin{array}{l}\text { My company has developed a project management curriculum (i.e., more than one or two courses) to enhance the project } \\
\text { management skills of our employees. }\end{array}$ & 2 \\
\hline & Total & 8 \\
\hline \multicolumn{3}{|c|}{ Phase: Executive management acceptance } \\
\hline 5 & $\begin{array}{l}\text { Our executives visibly support project management through executive presentations, correspondence, and by occasionally } \\
\text { attending project team meetings/briefings. }\end{array}$ & 3 \\
\hline 10 & The executives in my organization have a good understanding of the principles of project management. & 3 \\
\hline 13 & Our executives both understand project sponsorship and serve as project sponsors on selected projects. & 2 \\
\hline \multirow[t]{2}{*}{20} & $\begin{array}{l}\text { Our executives have demonstrated a willingness to change our way of doing business in order to mature in project } \\
\text { management. }\end{array}$ & 2 \\
\hline & Total & 10 \\
\hline \multicolumn{3}{|c|}{ Phase: line management acceptance } \\
\hline 7 & Our lower- and middle-level line managers totally and visibly support the project management process. & 1 \\
\hline 9 & $\begin{array}{l}\text { Our line managers are committed not only to project management, but also to the promises made to project managers for } \\
\text { deliverables. }\end{array}$ & 2 \\
\hline 12 & Our lower- and middle-level line managers have been trained and educated in project management. & 0 \\
\hline \multirow[t]{2}{*}{19} & Our lower- and middle-level line managers are willing to release their employees for project management training. & 1 \\
\hline & Total & 4 \\
\hline \multicolumn{3}{|c|}{ Phase: Growth } \\
\hline 4 & My company (or division) has a well-definable project management methodology using life cycle phases. & -3 \\
\hline 6 & My company is committed to quality up-front planning. We try to do the best we can at planning. & 2 \\
\hline 8 & My company is doing everything possible to minimize "creeping" scope (i.e., scope changes) on our projects. & 2 \\
\hline \multirow[t]{2}{*}{11} & The executives in my organization have a good understanding of the principles of project management. & 0 \\
\hline & Total & 1 \\
\hline
\end{tabular}

Phase: Maturity

My company has a system in place to manage both cost and schedule. The system requires charge numbers and cost account

codes. The system reports variances from planned targets.

15 My company has successfully integrated cost and schedule control for both managing projects and reporting status.

16 My company has developed a project management curriculum (i.e., more than one or two courses) to enhance the project management skills of our employees.

18 My company views and treats project management as a profession rather than a part-time assignment. Total 
describes the aggregated value for each question and the total values for each life cycle phase.

Based on these scores, some screening was conducted before moving on to the next phase in order to ensure that only immature issues would be further discussed. First of all, those issues related to the life cycle phases that had a score greater than or equal to +6 were removed, since they represent the phases that had been successfully completed from the perspective of Kerzner's (Kerzner, 2001) model. In this case, the first screening excluded the set of issues belonging to the first two phases: the embryonic and executive management acceptance ones.

A further screening evaluated the remaining issues related to the phases: line management acceptance, growth and maturity. This second screening considered the scores of the remaining issues individually. Given that the rating scale ranged from -3 (Strongly Disagree) to +3 (Strongly Agree), only the issues which scored below +2 were considered for further discussion. This is because, for questions with a minimum score of 2 points, it is understood that the participants agree or strongly agree that the issue has been incorporated into the daily organizational routine. Thus, it does not make sense to make additional efforts to improve them. The lines highlighted in bold in Table 1 represent the issues that remained after these two screenings.

\subsection{Thinking of values: creating plans of action}

The remaining issues represent the aspects of organizational project management that require special attention from senior managers. Thus, they were taken as the starting point for the reflective process in order to identify initiatives capable of improving organizational project management maturity.

Before creating what was to become the action plan, a deeper reflection on the results of the maturity model was made, in which the participants have to deal with numerous aspects related to organizational context, culture, limitations and experiences. This process was supported by Keeney's Value Focused Thinking (VFT) methodology (Keeney, 1996). The strategies proposed by Keeney (1996) were applied in discussion meetings in order to distinguish fundamental and means objectives, and to create the hierarchy of fundamental objectives and the means-ends objective network.

First of all, the aspects behind each question of the assessment form were identified and the issues were translated into initial objectives. Then, an extensive exploration of each issue was made by posing questions, such as: Did the aspects identified as immature make it difficult to achieve some results? Is the aspect identified as immature thus perceived by the organization? Is this aspect considered in the organization's strategy? What improvements would be offered by the development of this aspect? Why is it important for the organization? Based on the initial objectives, further questions were raised in order to explore in-depth why the objectives are important, what the organization is looking for by reaching a specific objective and what other objectives the company would like to achieve. For instance, a list of perceived objectives related to project maturity is presented in Table 2 below.

After identifying the organization's objectives, there was discussion on which ones represent fundamental objectives and which are means objectives as well as their relationships. To complete this task, three meetings were held with three members of the committee: the CEO and the 2 project managers

Table 2. Survey of objectives.

\begin{tabular}{|c|c|}
\hline \multicolumn{2}{|r|}{ Strategic Objectives } \\
\hline Incre & se the success rate of company's projects, improving organizational project management maturity. \\
\hline 1.0 & Increase functional managers' qualifications \\
\hline 1.1 & Support functional managers in the project management process \\
\hline 1.2 & Competence of functional managers \\
\hline 1.3 & Awareness of functional managers \\
\hline 2.0 & Minimize planning deviations \\
\hline 2.1 & Deviation in cost \\
\hline 2.2 & Deviation in time \\
\hline 2.3 & Deviation in scope \\
\hline 3.0 & Increase project managers' qualifications and skills \\
\hline 3.1 & Professionalization of project management \\
\hline 3.2 & Competence of project managers \\
\hline 3.3 & Awareness of project managers \\
\hline 4.0 & Maximize the alignment of project management practices and business strategies \\
\hline
\end{tabular}


whom he selected. The means-ends objective network resulting from the discussions is shown in Figure 4. This network relates the fundamental objectives to all others identified. An arrow from one objective to another indicates that achieving the former has an influence on achieving the latter.

It worthwhile noting that, as suggested by Alencar et al. (2011), to achieve the final results, first, one configuration for each interviewee was created. It was only after further discussions that a consensual configuration for the hierarchy of fundamental objectives and another for the means-end network for the problem were finally drawn up.

As Keeney suggests, thinking about how better to achieve these objectives can prompt the creation of alternatives in addition to which the results obtained in the previous steps help organizational values to be linked in order to produce more efficient decision opportunities and, thus, to enhance the likelihood of achieving these objectives. Once again the questions suggested by Keeney (1996) were used to explore the objectives and generate possible initiatives. A specific procedure was also applied that consists of analyzing each objective separately, then to analyzing each pair of objectives, then each three objectives and so on. Among the ideas generated, some were proper decision alternatives while others were a starting point for the creative process, and require a final revision.

Generating alternatives took a little longer than defining the objectives, even though only 3 members of the committee were involved. This was because apart from making various comparisons, initiatives need to be suggested that take the company's strategies and context into account. Thus, two meetings were held to think about possible alternatives and the third and final one dealt only with rethinking the whole list of alternatives and eliminating redundancies.

Finally, after further discussions, the group decided to analyze and identify training needs and to plan skills or other formal training for managers, to encourage and sponsor participation in workshops, courses, conferences, committees, and so forth. Moreover, it was decided to promote workshops/meetings on skills and, discussions and raising awareness of functional and project managers in order to encourage: 1) monitoring and supporting project management activities; 2) sponsoring employees' participation in workshops, courses, conferences, committees, etc.,

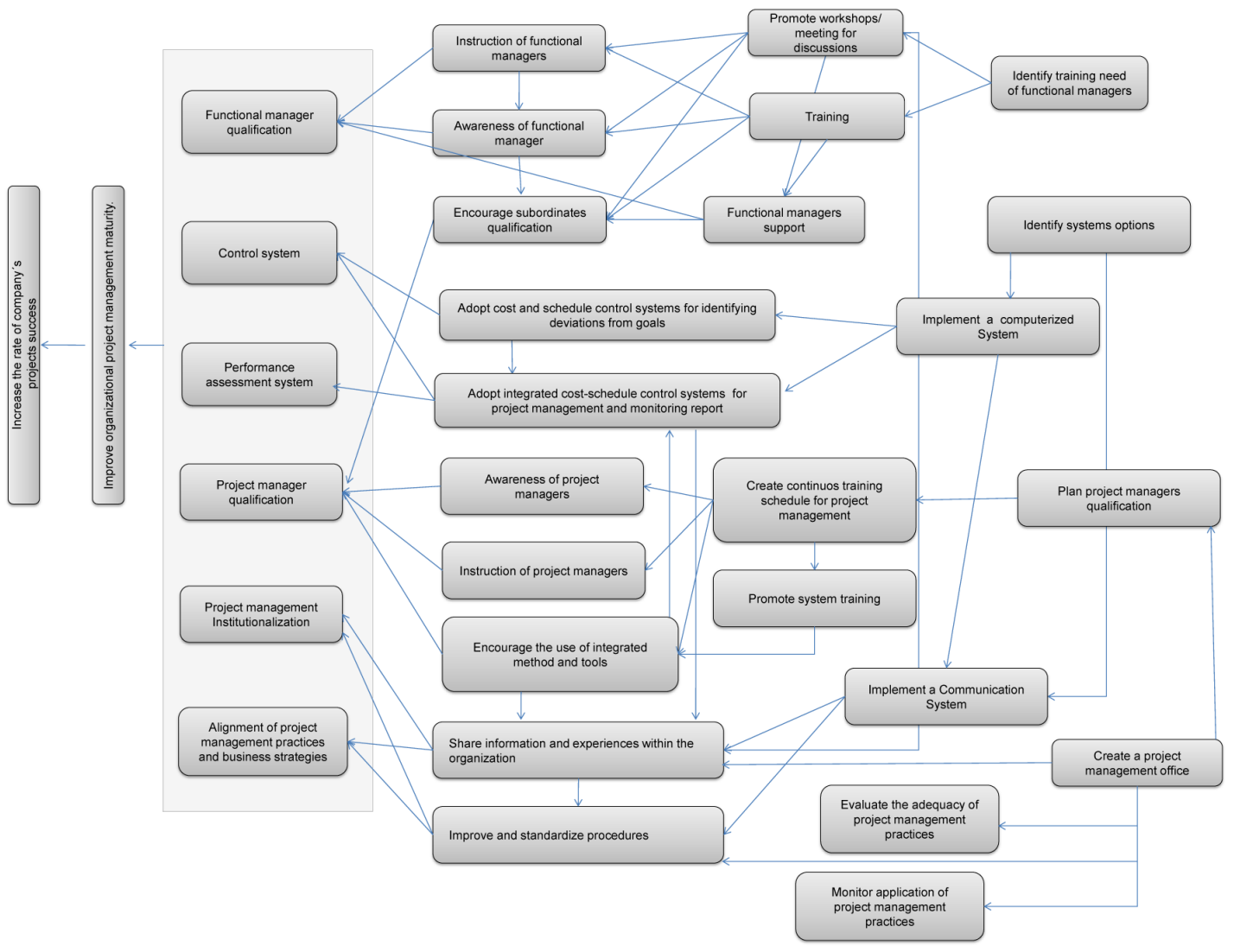

Figure 4. Means-end network. Source: Authors, 2014 
3) process innovation and 4) sharing information and experiences. This might be associated with a continuous and formal training program in project management within the organization.

As a system control was considered one of the critical issues, all decision-makers agreed to make a survey of systems options and to implement immediately a computerized systems control which ought to integrate cost-schedule management controls. As a consequence, mounting specific system training for employees will be necessary.

There was discussion on creating a project management office and a formal career in project management within the company. However, since a committee for monitoring projects was recently formed and the organizational structure remained as the matrix, the group decided to postpone this initiative, despite its great importance. Therefore, the committee was assigned the responsibility for: 1) emphasizing the use of standardized procedures, tools and methods; 2) developing and disseminating a unique methodology to manage projects; and 3) monitoring project management practices within the organization.

\subsection{Planning of initiatives, Implementation and follow-up of actions and Monitoring the results of the maturity plan}

The final steps of the proposed systematic correspond to the deployment of selected initiatives in smaller improvement actions, planning and the effective implementation of actions and reapplication of the PMMM questionnaire for follow-up. Unfortunately, the scope of this study was not able to cover the follow-up phase.

The monitoring of the plan as a whole is a new cycle of the proposed process that should be repeated as often as necessary to achieve the desired level of project management maturity. Within each new cycle, it is important to pay attention to the aspects that have not yet reached their goals by identifying potential errors and rethinking attitudes whenever this is necessary. The actions can and should be reformulated considering the lessons learned from implementing them and thus to ensure the plan is aligned with the strategies and goals.

\subsection{Discussion}

Although the present study did not cover the implementation phase, the intended objective was reached, since the aim was to evaluate the usefulness of integrating different decision-making models into the maturity evaluation process as a means to support decision-making on project management investments. The usefulness of applying the integrated framework was evaluated by gathering the feedback of the participants and comparing the results with those from applying a form that only assesses maturity.

Landry et al. (1983) argue that model building and validation should be intertwined into a model validating process based on various stages, such as the steps of the present action plan. The concept of validity needs a context, that is, a setting in which it can stand (Landry et al., 1983). For the authors, model validation refers to the extent to which the model fits the real system. Thus, the final approach supported by the participant's feedback can be considered as the output of the process for validating the model.

After applying the framework, a meeting was held with participants in order to have feedback on the process that had taken place. The participants identified that the main benefit of the integrated framework was the interactions conducted and the reflective process that pushes them to think more deeply about the real effects of implementing certain project management initiatives within the organizational context. They agreed that the process, especially, Value-focused Thinking methodology, leads to stimulating discussions and also more creative thoughts regarding how to improve project management. Group discussions were seen as very important for exchanging experience and knowledge among participants and very fruitful for the organizational learning process.

The participants observed that due to the group discussions, they felt greater commitment to the initiatives to be implemented and they seemed to be more confident and optimistic about the expected outcomes of their investment efforts. Moreover, the arguments presented during the different meetings were very useful for justifying what investments to choose and, thus, more easily supported.

In addition, the framework was shown to be very useful in directing the investment efforts in project management compared to the results from applying a questionnaire that only assesses maturity. In fact, we did not find any significant difference between the scores calculated by a simple mean and the one calculated with the voting procedure. This may have been a result of the association of the individuals with each other as they all were members of the project management committee and might have similar lines of thinking. If we had had participants from outside the committee, maybe there would have been more significant differences between the members.

The great benefit of the integrated framework was perceived by means of using a problem structuring 
method, the Value-focused Thinking methodology. After the maturity assessment, some PMMMs are limited to giving a list of recommended best practices to be implemented or capabilities that need to be improved. These take into account only the answers of the assessment form without encompassing other kinds of organizational concerns that are crucial for properly selecting and maximizing the returns on investments in project management. Some PMMMs provide optional tools in order to obtain guidelines on how to improve efforts. However the organization would then, additionally, have to meet the costs of having access to a specific tool or of a consultancy visit.

If an organization wants to continue the process on their own with no extra charges, managers would be induced to implement all recommended issues after applying the assessment. However, the case study revealed that even if the organization was able to implement all the recommended issues, which is not common, they would not do so due to their specific organizational context. In the case study of the company, the current organizational culture is not yet prepared to support certain initiatives. Thus, from the perspective of the participants the investment in certain initiatives would have a very low probability of success.

Furthermore, due to resource constraints, as is normal, after the maturity assessment managers would have to randomly prioritize the immature issues. Thus, investments efforts could take different directions, since decisions on what investments to make would be taken without making a holistic analysis. Therefore, the application of the Valuefocused Thinking methodology was very fruitful as this was used to conduct a further analysis of each immature issue taking into account all organizational concerns. For example, in this case study, a common PMMM would probably recommend the setting up of a project management office. However, due to the discussions held, the participants decided that this should not be an investment for now, at least not for the current organizational structure and culture, and that what was primarily needed was to make investments in training and system control.

Moreover, some difficulties during the process were highlighted. These included building the final configuration of the means-end network and identifying the measurement of each fundamental objective, both of which are addressed when applying the Value-focused Thinking methodology. In addition, the application of the problem structuring model was simplified as this study considered few issues and participants. In some situations, even after the screening phase, many issues may remain for the problem structuring process, thus greatly increasing the complexity of the further analysis, especially when one considers the number of pair-wise comparisons required to generate alternatives. An increasing number of participants would also make it difficult to reach a consensus and lead to longer discussions. For these reasons, it is extremely important that appropriately qualified and experienced professionals are appointed to conduct the process.

So far, the participants have expressed satisfaction with the final decisions taken through the process. The framework was shown to effectively support a holistic analysis of project management within the organization and, thus, leads to better decision-making regarding the investment efforts.

\section{Concluding remarks}

This paper presented an explicit procedure for supporting organizations in taking investment decisions with a view to improving organizational project management maturity. For this purpose, a literature review was conducted in order to develop a further understanding of PMMM frameworks, their main assumption and shortcomings. This produced some useful insights which aided discussion on how managers could make better and holistic decisions using the currently available PMMMs in order to maximize the return on their investments.

Then, a framework was provided that integrates different and distinct decision-making models. After a maturity evaluation is made to assess the strengths and weaknesses of project management, a group decision model is applied as a means to gather the perspectives of different participants. After having identified the immature project management issues which will be used as input, a problem structuring method is used, namely Value-focused Thinking (Keeney, 1996), which makes a holistic analysis that takes into account all organizational concerns in order to identify guidelines for fostering improved project management practice. The model seeks to support managers in maximizing their investment efforts, justifying the investments and gaining commitment from the people involved. An important feature of this process is its flexibility in adjusting the issues, actions, tools and techniques to the context of each organization, thus enabling its widespread use. Finally, a real application in a Brazilian public company showed the applicability of the approach.

\subsection{Theoretical implications}

As a theoretical contribution this paper brings together different concerns about PMMM frameworks and discusses how to enhance guidelines for maximizing 
project management investments. The literature review also showed the relevance of PMMMs within organizations as means of reaching tangible and intangible values (Berssaneti et. al., 2012; Moraes \& Kruglianskas, 2012; Thomas \& Mullaly, 2008). Moreover, it was seen that despite the sharp criticism made of them, PMMMs have been widely adopted. This is because organizations are continuously looking for ways to improve their project management capabilities (Albrecht \& Spang, 2014; Söderlund \& Maylor, 2012). These pieces of evidence reinforce the importance of PMMMs and call the attention of academics and professionals to the need for further discussion on PMMM frameworks, in particular with regard to the decision-making process for investment efforts. In putting forward an initial discussion, this study aimed to contribute to the advancement of project management maturity in organizations.

In addition, the integrated framework provides a new perspective on the decision-making process for organizational project management maturity in terms of concentrating on the alignment of the maturity issues and organizational strategies and context. Indeed, assessing the maturity level of the company is only part of the data needed to undertake strategic project management planning. There is a long way to go from this point before the effectiveness of the improvements can be confirmed. Pennypacker (2005) argues that the great differential obtained by adopting a maturity model should be the mapping of the path that will lead to the desired improvement being achieved.

\subsection{Practical implications}

The real case showed that the framework was easily understood by the participants and led to a structured and creative decision-making process. The framework supports the managerial decision-making process and, thus, contributes to the advancement of project management maturity within organizations. Managers might be able to create appropriate and effective action plans considering the organization's context and thereby maximize their investment efforts. It assists organizations to develop core competences that will enable them to create and maintain advantages over their competitors.

The proposed systematic enables the maturity model, the aggregation method and the problem structuring methodology to be replaced by tools and techniques that are more appropriate to the organizational context or with which the parties involved have greater familiarity. Thus, a relevant and practical characteristic of this framework is the flexibility to further extend its applicability in different contexts.

\subsection{Limitations and future studies}

The sample of individual maturity evaluation was one of the limitations of this study, since it was restricted to the 12 members of the committee. This might have limited the results of applying the voting procedure as discussed in the case study. Moreover, it was a transactional study, which limited the evaluation of the results from the investments. Thus, longitudinal studies would be fruitful in order to capture the results of the implementing the initiatives over time and, thus, to verify the benefits of the proposed approach for achieving organizational values. Further studies may also usefully explore each stage of the framework and propose other tools and techniques that could cope with increasing the number of issues and participants. Moreover, future research should focus on theoretical discussions about the current maturity evaluation process and seek different insights regarding the ability of PMMMs to reach their intended purpose of guiding organizations towards project management maturity.

\section{References}

Ahlemann, F., Teuteberg, F., \& Vogelsang, K. (2009). Project management standards - Diffusion and application in Germany and Switzerland. International Journal of Project Management, 27(3), 292-303. http://dx.doi.org/10.1016/j. ijproman.2008.01.009.

Albrecht, J. C., \& Spang, K. (2014). Linking the benefits of project management maturity to project complexity: Insights from a multiple case study. International Journal of Managing Projects in Business, 7(2), 285-301. http:// dx.doi.org/10.1108/1JMPB-08-2013-0040.

Alencar, L. H., Mota, C. M. M., \& Alencar, M. H. (2011). The problem of disposing of plaster waste from building sites: problem structuring based on value focus thinking methodology. Waste Management, 31(12), 2512-2521.http:// dx.doi.org/10.1016/j.wasman.2011.06.015 PMid:21816597.

Andersen, E. S., \& Jessen, S. A. (2003). Project maturity in organizations. International Journal of Project Management, 21(6), 457-461. http://dx.doi.org/10.1016/S02637863(02)00088-1.

Berssaneti, F. T., Carvalho, M. M., \& Muscat, A. R. N. (2012). Impacto dos modelos de referência e maturidade no gerenciamento de projetos: estudo exploratório em projetos de tecnologia da informação. Produção, 22(3), 404-435.

Besner, C., \& Hobbs, B. (2008a). Discriminating contexts and project management best practices on innovative and noninnovative projects. Project Management Journal, 39(S1), S1-S123. http://dx.doi.org/10.1002/pmj.20064.

Besner, C., \& Hobbs, B. (2013). Contextualized project management practice: a cluster analysis of practices and best practices. Project Management Journal, 44(1), 17-34. http://dx.doi.org/10.1002/pmj.21291. 
Bose, U., Davey, A. M., \& Olson, D. L. (1997). Multi-attribute utility methods in group decision-making: past applications and potential for inclusion in GDSS. Omega, 25(6), 691706. http://dx.doi.org/10.1016/S0305-0483(97)00040-6.

Brookes, N., \& Clark, R. (2009). Using maturity models to improve project management practice. In POMS 20th Annual Conference, Orlando, Florida.

Bushuyev, S. D., \& Wagner, R. F. (2014). IPMA Delta and IPMA Organisational Competence Baseline (OCB): New approaches in the field of project management maturity. International Journal of Managing Projects in Business, 7(2), 302-310. http://dx.doi.org/10.1108/lJMPB-10-2013-0049.

Cleland, D. 1., \& King, W. R. (1999). Project management: strategic design and implementation (3rd ed.). New York: McGraw-Hill.

CMMI Product Team. (2001). Capability Maturity Model ${ }^{\circledR}$ Integration (CMMISM), Version 1.1. Software Engineering Institute, Carnegie Mellon University.

Cooke-Davies, T. J. (2007). Project management maturity models. In P. W. G. Morris \& J. K. Pinto (Eds.), The Wiley guide to project organization and project management competencies (pp. 290-311). Hoboken: Wiley.

Cooke-Davies, T. J., \& Arzymanow, A. (2003). The maturity of project management in different industries: An investigation into variations between project management models. International Journal of Project Management, 21(6), 471478. http://dx.doi.org/10.1016/S0263-7863(02)00084-4.

Crawford, J. K. (2002). The strategic project office: a guide to improving organizational performance. New York: Marcel Dekker.

Crawford, J. K. (2006). The project management maturity model. Information Systems Management, 23(4), 50-58. http://dx.doi.org/10.1201/1078.10580530/46352.23.4.2 $0060901 / 95113.7$.

Cristofari Junior, C. A., Paula, l. C., \& Fogliatto, F. S. (2010). Método de análise de maturidade e priorização de melhorias na gestão do processo de desenvolvimento de produtos. Produção, 20(3), 359-377.

Dietrich, P., \& Lehtonen, P. (2005). Successful management of strategic intentions through multiple projects - Reflections from empirical study. International Journal of Project Management, 23(5), 386-391. http://dx.doi.org/10.1016/j. ijproman.2005.03.002.

Eden, C., Jones, S., \& Sims, D. (1983). Messing about in problems. 0xford: Pergamon.

Grundy, T. (2000). Strategic project management and strategic behavior. International Journal of Project Management, 18(2), 93-103. http://dx.doi.org/10.1016/S0263-7863(98)00076-3.

Guedes, R. M., Gonçalves, M. A., Laurindo, F. J. B., \& Maximiano, A. C. A. (2014). Maturidade de gestão de projetos de sistemas de informação: um estudo exploratório quantitativo no Brasil. Produção, 24(2), 364-378.

lbbs, C. W., \& Kwak, Y. H. (2000). Assessing project management maturity. Project Management Journal, 31(1), 32-43.

International Project Management Association - IPMA. (2013). IPMA Organizational Competence Baseline. The standard for moving organizations forward. Amsterdam.

Jia, G., Chen, Y., Xue, X., Chen, J., Cao, J., \& Tang, K. (2011). Program management organization maturity integrated model for mega construction programs in China. International Journal of Project Management, 29(7), 834-845. http:// dx.doi.org/10.1016/j.ijproman.2011.03.003.
Jugdev, K., \& Thomas, J. (2002). Project management maturity models: The silver bullets of competitive advantage? Project Management Journal, 33(4), 4.

Keeney, R. L. (1996). Value-focused thinking: identifying decision opportunities and creating alternatives. European Journal of Operational Research, 92(3), 537-549. http:// dx.doi.org/10.1016/0377-2217(96)00004-5.

Kerzner, H. (2001). Strategic planning for project management: using the project management maturity model. New York: John Wiley \& Sons.

Kerzner, H. (2004). Advanced project management: best practices on implementation (2nd ed.). New York: John Wiley \& Sons.

Kerzner, H. (2006). Maturity: do or die? PM Network, 30-35.

Killen, C. P., \& Hunt, R. A. (2009). Project portfolio management maturity model for dynamic environments. In Proceedings of the Australian Institute of Project Management (AIPM) Conference, Adelaide.

Killen, C. P., \& Hunt, R. A. (2013). Robust project portfolio management: capability evolution and maturity. International Journal of Managing Projects in Business, 6(1), 131-151. http://dx.doi.org/10.1108/17538371311291062.

Kujala, J., \& Artto , K. (2000). Criteria for project performance in business context. Project Management Journal, 6(1), 46-53.

Kwak, Y. H., \& lbbs, C. W. (2000). Calculating project management's return on investment. Project Management Journal, 31(2), 38-47.

Kwak, Y.H., \& lbbs, C.W. (2002). Assessing project management maturity. Journal of Management in Engineering, 18(3), 150-155. http://dx.doi.org/10.1061/(ASCE)0742597X(2002) 18:3(150).</jrn>.

Landry, M., Malouin, J. L., \& Oral, M. (1983). Model Validation in Operations Research. European Journal of Operational Research, 14(3), 207-220. http://dx.doi.org/10.1016/03772217(83)90257-6.

Leyva-López, J. C., \& Fernandéz-González, E. (2003). A new method for group decision support based on ELECTRE 111 methodology. European Journal of Operational Research, 148(1), 14-27. http://dx.doi.org/10.1016/S03772217(02)00273-4.

Meskendahl, S. (2010). The influence on business strategy on project portfolio management and its success - A conceptual framework. International Journal of Project Management, 28(8), 807-817. http://dx.doi.org/10.1016/j. ijproman.2010.06.007.

Miguel, P. A. C. (2007). Estudo de caso na engenharia de produção: estruturação e recomendações para sua condução. Produção, 17(1), 216-229.

Moraes, R. 0., \& Kruglianskas, 1. (2012). 0 gerente de projetos de $\mathrm{Tl}$ em organizações com níveis de maturidade diferenciados. Produção, 22(4), 839-850.

Morais, D. C., \& Almeida, A. T. (2007). Group decision-making for leakage management strategy of water network. Resources, Conservation and Recycling, 52(2), 441-459. http://dx.doi. org/10.1016/j.resconrec.2007.06.008.

Mullaly, M. (2006). Longitudinal analysis of project management maturity. Project Management Journal, 36(3), 62-73.

Mullaly, M. (2014). If maturity is the answer, then exactly what was the question? International Journal of Managing Projects in Business, 7(2), 169-185. http://dx.doi.org/10.1108/ IJMPB-09-2013-0047. 
Nurmi, H. (1983). Voting procedures: A summary analysis. B.J. Pol. S., 13(02), 181-208. http://dx.doi.org/10.1017/ S0007123400003215.

Pasian, B. L., Williams, N., \& Alameri, H. (2012). The value of project management maturity models: a new conceptual model with a resource-based view. In Proceedings of 26th IPMA World Congress, Crete.

Pennypacker, J. S. (2005). PM SOLUTIONS' Project Portfolio Management Maturity Model. Pennsylvania: Center for Business Practices.

Programme and Project Management Maturity Model - P3M3. (2010). Introduction and Guide to P3M3. Version 2.1. England: Office of Government Commerce.

Project Management Institute - PMl. (2008). Organizational Project Management Maturity Model (OPM3). (2nd ed.). Newtown Square.

Project Management Institute - PMI. (2012). Pulse of the profession. Newtown Square. Retrieved in 10 February 2013, from <http://www.pmi.org/business-solutions/pulse.aspx

Rabechini Junior, R., \& Pessôa, M. S. P. (2005). Um modelo estruturado de competências e maturidade em gerenciamento de projetos. Produção, 15(1), 34-43.

Saari, D. G. (1999). Explaining all three-alternative voting outcomes. Journal of Economic Theory, 87(2), 313-355. http://dx.doi.org/10.1006/jeth.1999.2541.

Shi, Q. (2011). Rethinking the implementation of project management: a value adding path map approach. International
Journal of Project Management, 29(3), 295-302. http:// dx.doi.org/10.1016/j.jproman.2010.03.007.

Simpson, J. A., \& Weiner, E. S. C. (Eds.). (1989). The Oxford english dictionary (2nd ed.). Oxford: University Press. Retrieved in 20 May 2014, from http://findwords.info/ term/maturity

Söderlund, J., \& Maylor, H. (2012). Project management scholarship: Relevance, impact and five integrative challenges for business and management schools. International Journal of Project Management, 30(6), 686-696. http://dx.doi. org/10.1016/j.ijproman.2012.03.007.

Tellis, W. (1997). Application of a case study methodology. Qualitative Report, 3(3), 7.

Thomas, J., \& Mullaly, M. (2008). Researching the value of project management. Newtown Square: Project Management Institute.

Wendler, R. (2012). The maturity of maturity model research: a systematic mapping study. Information and Software Technology, 54(12), 1317-1339. http://dx.doi.org/10.1016/j. infsof.2012.07.007.

Williams, N., Ferdinand, N. P., \& Croft, R. (2014). Project management maturity in the age of big data. International Journal of Managing Projects in Business, 7(2), 311-317. http://dx.doi.org/10.1108/IJMPB-01-2014-0001.

Yin, R. K. (2001). Estudo de caso: planejamento e método (2. ed.). São Paulo: Bookman. 